\title{
Kahramanmaraş Kentinde Güneş Enerjisi Destekli Absorpsiyonlu Soğutma Sistemi Kullanılarak Bir Apartman Dairesinin Soğutulması
}

\author{
Muhammed Enes KUYUMCU ${ }^{1 *}$, Hüseyin Emre ŞAHİN ${ }^{1}$, Recep YUMRUTAŞ ${ }^{2}$, Muharrem IMAL ${ }^{1}$ \\ ${ }^{1}$ Kahramanmaraş Sütçü İmam Üniversitesi, Mühendislik ve Mimarlık Fakültesi, Makina Mühendisliği Bölümü, \\ 46100-Kahramanmaraş \\ ${ }^{2}$ Gaziantep Üniversitesi, Mühendislik Fakültesi, Makina Mühendisliği Bölümü, 27310-Gaziantep
}

\begin{abstract}
ÖZET: Bu çalışmada, güneş enerjisi destekli tek etkili Su-Lityum Bromür $\left(\mathrm{H}_{2} \mathrm{O}-\mathrm{LiBr}\right)$ karışımı kullanan absorpsiyonlu soğutma makinası kullanılarak Kahramanmaraş kentinde inşa edilmiş bir apartman dairesinin soğutulması sağlanmıştır. Çalışmada, TS 825 standartları ve Kahramanmaraş kentinin yaz hava koşulları göz önüne alınmıştır. Odalarda istenilen sabit iç ortam sıcaklığını korumak için hesaplanan soğutma enerjisi ihtiyacı, absorpsiyonlu soğutma sisteminin kolektörleri vasıtasıyla güneş enerjisinden karşılanmıştır. Hesaplamalarda Engineering Equation Solver (EES) ve Matrix Laboratory (MATLAB) programları kullanılmıştır. Apartman dairesinin soğutma enerjisi talebine göre farklı tip kolektörler (düz plakalı ve vakum tüplü kollektör) göz önüne alınarak gerekli olan kolektör yüzey alanı hesaplanmıştır.
\end{abstract}

Anahtar kelimeler: Absorpsiyonlu Soğutma, Güneş Enerjisi, Güneş kolektörü, Etkinlik katsayısı.

\section{Cooling of an Apartment by Using Absorption Refrigeration System in the City of Kahramanmaraş}

\begin{abstract}
In this study, cooling of an apartment constructed in the city of Kahramanmaraş by using solar-assisted single effect absorption refrigeration machine, which uses water-lithium bromide (H2O-LiBr) mixture, has been provided. In the study, TS 825 standard and summer weather conditions of the city of Kahramanmaraş have been considered. In order to maintain the desired rooms's constant indoor temperature, the calculated cooling energy requirement has been met from the solar energy by means of collectors of the solar assisted absorption cooling system. In calculations Engineering Equation Solver (EES) and The Matrix Laboratory (MATLAB) programs were used. According to the apartment's cooling energy demand, required collector surface area has been calculated by considering different types of collectors (flat plate and evacuated tube collectors).
\end{abstract}

Keywords: Absorption Refrigeration, Solar Energy, Solar collector, Coefficient of performance.

\section{GİRIS}

Günümüzde enerji ve yenilenebilir enerji kaynakları büyük önem arz etmektedir. Enerji talebinin artması, küresel ısınma ve ekolojik etkiler göz önüne alındığında, enerji elde etmek için çevreyi kirleten kömür ve fosil yakıtlar yerlerini, güneş enerjisi gibi temiz ve yenilenebilir enerji kaynaklarına bırakmaya başlamışlardır. Bu nedenle, güneşlenme sürelerinin uzun olduğu ülkemizde, temiz ve çevre dostu olan yenilenebilir enerji kaynağı güneşe yönelmek doğru bir tercih olacaktır.

Isıl konfor insanların hayatını etkileyen önemli bir faktördür. Sağlıklı bir hayat için kişilerin zaman geçirdikleri ortamların belirli sıcaklıklarda sabit tutulması gereklidir. Bu nedenle, yaz aylarında insanların yaşamlarını sürdürdükleri dairelerin, konfor şartlarının sağlanması için soğutulması gerekmektedir. Çoğunlukla bu soğutma işlemi, elektrik enerjisi tüketimi yüksek olan geleneksel klima sistemleriyle yapılmaktadır. Fransız Ferdinand Carre tarafından bulunan ısı enerjisi ile çalışan absorbsiyonlu soğutma sisteminin, güneş enerjisinin en çok olduğu yaz aylarında kullanılması uygun bir tercih olacaktır. [1]

Kapalı mahallerin soğutulması ve absorpsiyonlu soğutma sistemi ile ilgili literatürde pek çok çalışmaya rastlanmaktadır. Örneğin; Eskin ve Türkmen, farklı boyutlarda ve farklı şehirlerde bulunan ofis amaçlı binaların y1llı 1sıtma ve soğutma yüklerinin hesaplanmasını binanın büyüklüğü, iklim şartları, cam tipleri, pencere oranları, çerçeve tipleri ve kullanım faktörlerine bağlı olarak yapmıştır [2]. Kent ve Kaptan, İzmir ilinde bir otelin 1sıtma ve soğutma ihtiyacını SuLityum Bromür $\left(\mathrm{H}_{2} \mathrm{O}-\mathrm{LiBr}\right)$ karışımı kullanan güneş enerji destekli absorpsiyonlu sistemle sağlayarak toplam maliyet ve geri ödeme süresi üzerine teorik çalışma 
yapmıştır [3]. Kuyumcu vd., güneş enerjisi destekli absorpsiyonlu soğutma sistemi ile buz pistinin soğutulmasını ele alarak teorik olarak incelemiş ve sistem parametrelerini değiştirerek gerekli olan optimum kollektör miktarını belirlemişlerdir [4]. Onan vd., güneş enerjisi destekli absorpsiyon soğutma sistemi Mardin şehrinde bulunan bir villa için tasarlamış ve farklı sicaklıklar altında sistemin performansı MATLAB programı kullanarak analiz etmişlerdir [5]. Cimşit ve Öztürk, buhar sıkıştırmalı-absorpsiyonlu çift kademeli soğutma çevrimi tasarlamış ve çevrimin termodinamik analizini yapmışlardır. Akışkan olarak buhar sıkıștırmalı kısmında $\mathrm{NH}_{3}$ soğutucu akışkanı absorpsiyonlu kısımda ise $\mathrm{NH}_{3}-\mathrm{H}_{2} \mathrm{O}$ kullanmışlardır [6]. Bozkaya ve Akdemir, 5 aylık soğutma sezonunda İzmir ili için güneş enerji destekli tek etkili $\mathrm{NH}_{3}-\mathrm{H}_{2} \mathrm{O}$ ile çalışan absorpsiyonlu soğutma sisteminin, soğutma yükünü karşılaması amacıyla uygun kollektör alanını belirlemişlerdir [7]. Öz vd., vakum tüplü güneş enerjili su 1sıtma sistemi ile standart düz kollektörlü su 1sıtma sisteminin performans ve verimleri deneysel olarak araştırmış, kollektörlerin performans ve verimini belirlemişlerdir [8].
Bu çalışmada, Kahramanmaraş kent merkezinde yer alan Güney-Batı yönünde brüt $110 \mathrm{~m}^{2}$ alana sahip bir apartman dairesinin soğutma ihtiyacı TS825 standartlarına göre hesaplanmıştır. Burada enerji analizi, Kahramanmaraş kentinin hava koşulları göz önüne alarak yapılmıştır. $\mathrm{Bu}$ dairenin toplam soğutma 1s1 yükünü karşılaması için güneş enerjisi destekli çalışan tek etkili Su-Lityum Bromür $\left(\mathrm{H}_{2} \mathrm{O}-\mathrm{LiBr}\right)$ karışımı kullanan absorpsiyonlu soğutma makinası kullanılmıştır. Sistemin ihtiyacı olan enerjiyi karşılayabilmek için gerekli olan kollektör yüzey alanı farklı tip kolektörler (düz plakalı ve vakum tüplü kollektör) göz önüne alınarak hesaplanmıştır.

\section{SİSTEMIN TANIMI}

Apartman dairesinin soğutma sistemi; absorpsiyonlu soğutma çevrimiyle çalışan soğutma makinası, güneş kollektörleri ve ihtiyaç durumunda kullanılacak olan boyler bileşenlerinden oluşmaktadır ve basitçe Şekil 1'de gösterilmiştir.

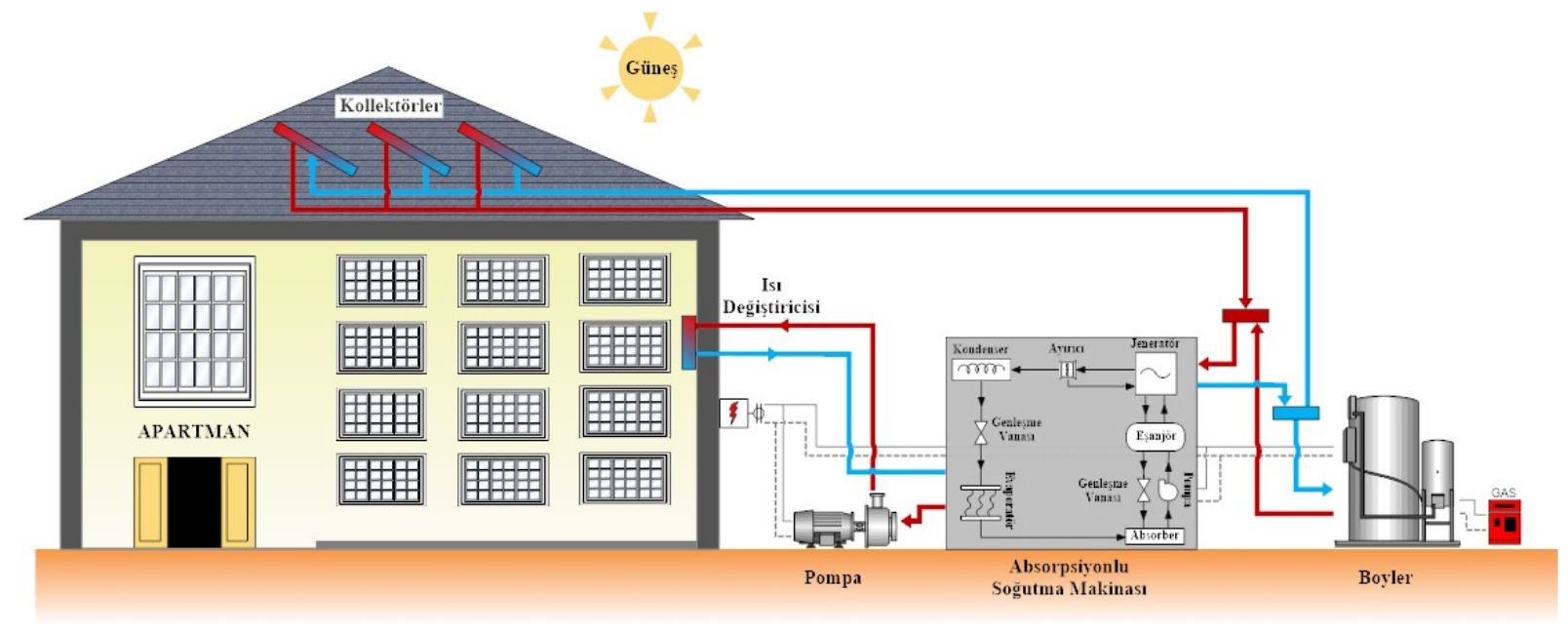

Şekil 1. Güneş enerjisi destekli absorpsiyonlu soğutma makinası ile soğutulan bir apartman dairesinin soğutma sistemi.

Dairenin $37^{\circ} 35^{\prime}$ Kuzey enlem ve $36^{\circ} 55^{\prime}$ Doğu boylamları arasında yer alan ve $572 \mathrm{~m}$ rakıma sahip Akdeniz iklimi özelliklerini gösteren Kahramanmaraş kentinde inşa edilmiștir. Dairede 3 yatak odasının, 1 salonun ve 1 mutfağın soğutulacağı düşünülmüş ve Şekil 2'de apartman dairesinin planı verilmiştir.

Daire binanın 3. katında ve Güney-Batı yönünde bulunmaktadır. Daire $2.75 \mathrm{~m}$ tavan yüksekliğine, kullanılan kapılar $2 \times 1 \mathrm{~m}^{2}$ ve pencereler $1.5 \times 2 \mathrm{~m}^{2}$ boyutlara sahiptir. Dairede 3 yatak odası $\left(9,12,15 \mathrm{~m}^{2}\right)$ toplam $36 \mathrm{~m}^{2}$, salon $25 \mathrm{~m}^{2}$ ve mutfak $9 \mathrm{~m}^{2}$ büyüklüğündedir ve iki çocuklu dört kişilik bir ailenin ikamet ettiği düşünülmüştür.
Apartman dairesinin soğutma sisteminin çalışma prensibi k1saca şöyledir; absorpsiyonlu soğutma makinasının jeneratörüne güneşten elde edilen faydalı 1s1 aktarılır ve sistemin ihtiyacı olan enerji sağlanmış olur. Eğer talep edilen enerji güneşten sağlanamazsa boyler devreye girer ve sistem desteklenmiş olur. Daha sonra termodinamik çevrim sırasında evaporatör, daireyi soğutmak için odalardan 1sıyı soğuran fan-coil sirkülasyon sisteminden $1 \mathrm{~S} 1$ değiştiricisi vasıtasıyla $1 \mathrm{~S} 1$ çeker. Böylece, güneş enerjisi ile absorpsiyonlu soğutma makinası kullanılarak bir daire soğutulmuş olur. $\mathrm{Bu}$ sistemde, dairenin odaları için istenilen ortam sıcaklığına önceden ulaşıldığı varsayılıp ön soğutma 1s1 yükü göz önüne alınmamıştır. 


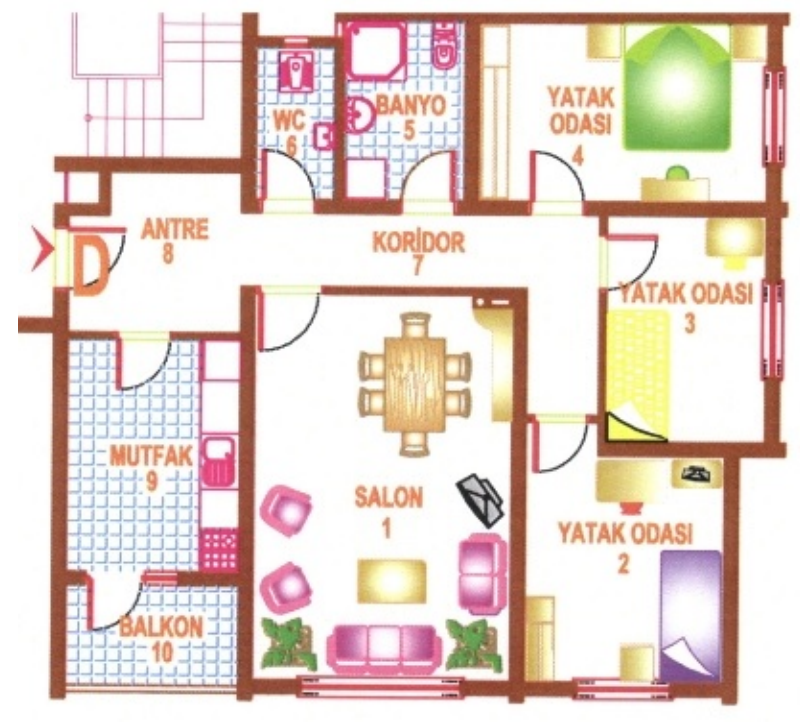

Şekil 2. Apartman dairesinin planı.

\section{SISTEMIN MODELLENMESI}

Güneş enerjisi destekli absorpsiyonlu soğutma makinası ile soğutulan bir apartman dairesinin soğutma sisteminin modellenmesi bu bölümde yapılmıştır. Öncelikle TS 825 standardına göre dairedeki her odanın soğutulması için gerekli olan toplam enerji, soğutma 1s1 yükü bileşenleri göz önüne alınarak hesaplanmıştır. Daha sonra, odalar için talep edilen toplam soğutma 1s1 yükünün karşılanabilmesi için absorpsiyonlu soğutma makinasının jeneratörüne verilmesi gereken isı ve sistemin COP değeri belirlenmiştir. Elde edilen sonuçlara göre bu ısıyı elde etmek için gerekli kollektör yüzey alanı hesaplanmıştır.

\subsection{Apartman dairesinin toplam soğutma ısı yükü}

Apartman dairesindeki her bir oda için istenilen ortam sıcaklığını sabit tutabilmek için yaz koşullarında dairenin toplam soğutma 1sı yükünün karş1lanması gerekmektedir. Odalar için istenilen tasarım koşulları göz önüne alınarak dairenin toplam soğutma 1sı yükü aşağıdaki formülle hesaplanabilir [9].

$$
Q_{\text {Daire }}=Q_{\text {Oda }} \times Z+Q_{S}+Q_{\text {Insan }}+Q_{\text {Cihaz }}
$$

burada $Q_{\text {Oda }}$ odalar için artırımsız 1sı kazancıdır, $Z$ birleştirilmiş artırım katsayısıdır, $Q_{S}$ hava sızıntısı ısı kazancıdır, $Q_{\text {Insan }}$ insanlardan olan 1S1 kazancidır ve $Q_{\text {Cihaz }}$ cihazlardan olan 1sı kazancıdır. $Q_{\text {Oda }}$ odalar için artırımsız ısı kazancı aşağıdaki şekilde hesaplanır.

$Q_{\text {Oda }}=Q_{d}+Q_{i k}+Q_{p}$

burada $Q_{d}$ iç ve dış duvarlardan kaynaklanan toplam 1sı kazancıdır, $Q_{i k}$ iç kapıdan kaynaklanan ısı kazancıdır ve
$Q_{p}$ pencereden kaynaklanan ısı kazancıdır. $Q_{d}, Q_{i k}$ ve $Q_{p}$ 1sı kazançları aşağıdaki formüllerle hesaplanır.

$Q_{d, i k, p}=U_{d, i k, p} \cdot A_{d, i k, p} \cdot \Delta T_{d, i k, p}$

burada $A$ toplam alan, $\Delta T=T-T_{\text {iç }}$ sicaklık farkı ve $U$ toplam 1S1 transfer katsayısıdır. Duvar toplam 1s1 transfer katsayısı $U_{d}$ aşağıdaki şekilde hesaplanır.

$\frac{1}{U_{d}}=\frac{1}{h_{i c ̧}}+\frac{d_{s}}{k_{s}}+\frac{d_{t}}{k_{t}}+\frac{d_{s}}{k_{s}}+\frac{1}{h_{d i s ̧}}$

burada $d$ duvar bileşeni kalınlığı, $h$ 1sı taşınım katsayıs1 ve $k$ 1s i iletim katsayısıdır. Apartman dairesinde kullanılan yapı bileşenlerinin termal özellikleri [9] ve boyutları Tablo 1'de verilmiştir.

Tablo 1. Apartman dairesinde kullanılan yapı bileşenlerinin özellikleri.

\begin{tabular}{|c|c|c|c|}
\hline $\begin{array}{l}\text { Yapı } \\
\text { Bileşeni }\end{array}$ & $\begin{array}{c}\mathbf{k} \\
\left(\mathrm{W} / \mathbf{m}^{0} \mathrm{C}\right) \\
\end{array}$ & $\begin{array}{c}h \\
\left(W / m^{20} C\right)\end{array}$ & $\begin{array}{c}\mathrm{U} \\
\left(\mathrm{W} / \mathrm{m}^{20} \mathrm{C}\right)\end{array}$ \\
\hline Siva & 0,87 & - & - \\
\hline Tuğla & 0,50 & - & - \\
\hline İç Kapı & - & - & 2,0 \\
\hline Pencere & - & - & 2,5 \\
\hline İç Ortam & - & 10 & - \\
\hline Diş Ortam & - & 20 & - \\
\hline
\end{tabular}

Z birleştirilmiş artırım katsayısı aşağıdaki şekilde bulunur.

$$
Z=1+Z_{D}+Z_{W}+Z_{H}
$$

burada, $Z_{D}$ birleşik artırım katsayısıdır ve daire 2 . işletme şartlarına uyduğundan $\% 15$ alınmıştır. $Z_{W}$ kat yüksekliği katsayısıdır ve daire üçüncü kattan yüksek olmadığı için $\% 0$ alınmıştır. $Z_{H}$ yön faktörüdür ve Güney-Batı için $+\% 5$ alınmıştır [9].

$Q_{S}$ hava sızıntısı 1sı kazancı aşağıdaki formülle hesaplanır.

$Q_{s}=\frac{1}{3.6} \sum(a l) O_{d k} H \Delta T Z_{e}$

burada, $a$ sızdırganlık katsayısı, $l$ dış duvar üzerinde bulunan kapı veya pencerelerin açılan kısımlarının çevre uzunluğu, $O_{d k}$ oda durum katsayısı, $H$ bina durum katsayısı, $\Delta T=T-T_{\text {iç }}$ sıcaklık farkı ve $Z_{e}$ köşe açıklıkları etki katsayısıdır. Tablo 2'de hava sızıntısı 1sı kazancı bileşenleri verilmiştir [9]. 
Tablo 2. Apartman dairesi hava sızıntısı 1sı kazanc1 bileşenleri.

\begin{tabular}{lc}
\hline Bileşen & Değeri \\
\hline$a$ sızdırganlık katsayısı $\left(\mathrm{m}^{3} / \mathrm{mh}\right)$ & 1,50 \\
$l$ dış duvar üzerinde bulunan kapı & \\
veya pencerelerin açılan & 42 \\
kısımlarının çevre uzunluğu $(\mathrm{m})$ & \\
$O_{d k}$ oda durum katsayısı & 0,70 \\
$H$ bina durum katsayısı $\left(\mathrm{kJ} / \mathrm{m}^{30} \mathrm{C}\right)$ & 2,43 \\
$Z_{e}$ köşe açıklıkları etki katsayısı & 1,00 \\
\hline
\end{tabular}

Dairede sürekli çalışan cihazlardan olan ısı kazancı ( $Q_{\text {Cihaz }}$ ) Tablo 3’te verilmiştir.

Tablo 3. Cihazlardan olan 1s1 kazanc1.

\begin{tabular}{lc}
\hline Elektrikli cihazlar & Isı kazancı (W) \\
\hline A++ Buzdolabı & 500 \\
Televizyon & 250 \\
Bilgisayar & 125 \\
\hline
\end{tabular}

İki çocuklu dört kişilik bir ailede insanlardan olan 1s1 kazancı aşağıdaki şekilde bulunur.

$Q_{\text {insan }}=130 \times N_{k s}$

burada, $N_{k s}$ kişi sayısıdır.

\subsection{Absorpsiyonlu soğutma makinasının analizi}

Buhar sıkıştırmalı soğutma makinelerinde kullanılan kompresörün yerine, absorpsiyonlu soğutma makinesinde termal prosesler kullanılarak soğutucu akışkanın basıncı arttırılır. Absorpsiyonlu soğutma makinesi kondenser, evapararator, absorber, jeneratör ve pompadan oluşur ve sistemde iki akışkan çiftinden oluşan solüsyon kullanılır. Apartman dairesinin soğutulmasında kullanılan güneş enerjisi destekli tek etkili Su-Lityum Bromür $\left(\mathrm{H}_{2} \mathrm{O}-\mathrm{LiBr}\right)$ karışımı kullanan absorpsiyonlu soğutma makinasının şematik gösterimi Şekil 3'te verilmiştir.

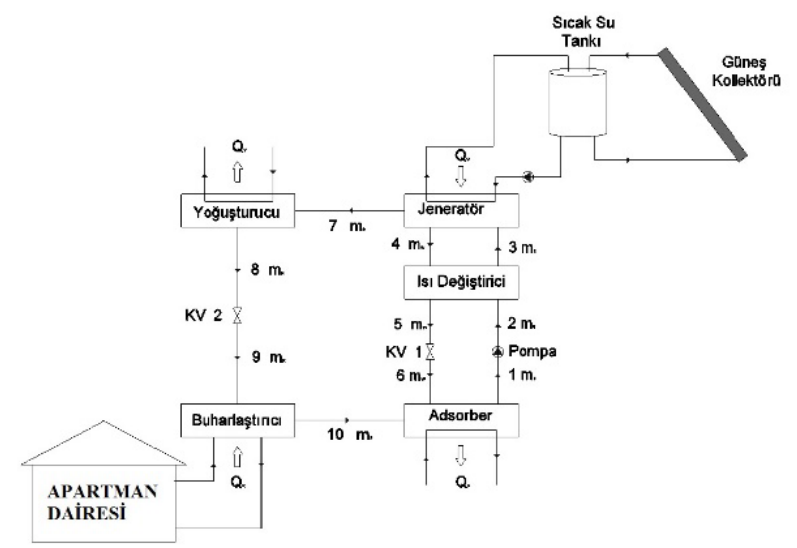

Şekil 3. Güneş enerjisi destekli tek etkili Su-Lityum Bromür $\left(\mathrm{H}_{2} \mathrm{O}-\mathrm{LiBr}\right)$ karışımı kullanan absorpsiyonlu soğutma makinasının şematik gösterimi.

$\mathrm{Bu}$ çalışmada absorpsiyonlu soğutma makinasının her bir sistem elemanı için Tablo 4'te verilen kütle ve enerji denge denklemleri çıkartılmış ve EES programında elde edilen bu denklemler kullanılarak absorpsiyonlu soğutma makinasının enerji analizleri yapılmıştır.

Tablo 4. Absorpsiyonlu soğutma makinasının her bir sistem elemanı için kütle ve enerji denge denklemleri.

\begin{tabular}{lcc}
\hline Sistem Elemanları & Kütlenin Korunumu & Enerjinin Korunumu \\
\hline Absorber & $\dot{m}=\dot{m}_{6}+\dot{m}_{10}$ & $\dot{m}_{6} h_{6}+\dot{m}_{10} h_{10}-\dot{m}_{1} h_{1}-\dot{Q}_{A}=0$ \\
Pompa & $\dot{m}_{1}=\dot{m}_{2}$ & $\dot{m}_{1} h_{1}-\dot{m}_{2} h_{2}+\dot{W}_{P}=0$ \\
Isı Değiştirici & $\dot{m}_{2}=\dot{m}_{3}, \dot{m}_{4}=\dot{m}_{5}$ & $\dot{m}_{2}\left(h_{2}-h_{3}\right)=\dot{m}_{4}\left(h_{4}-h_{5}\right)$ \\
Jeneratör & $\dot{m}_{3}=\dot{m}_{4}+\dot{m}_{7}$ & $\dot{m}_{3} h_{3}-\dot{m}_{4} h_{4}-\dot{m}_{7} h_{7}+\dot{Q}_{G}=0$ \\
Kısılma Vanası 1 & $\dot{m}_{5}=\dot{m}_{6}$ & $h_{5}=h_{6}$ \\
Kondenser & $\dot{m}_{7}=\dot{m}_{8}$ & $\dot{m}_{7} h_{7}-\dot{m}_{8} h_{8}-\dot{Q}_{K}=0$ \\
Kısılma Vanası 2 & $\dot{m}_{8}=\dot{m}_{9}$ & $h_{8}=h_{9}$ \\
Evaparatör & $\dot{m}_{9}=\dot{m}_{10}$ & $\dot{m}_{9} h_{9}-\dot{m}_{10} h_{10}+\dot{Q}_{E}=0$ \\
\hline
\end{tabular}

\subsection{Kollektör yüzey alanının belirlenmesi}

Soğutma sisteminin çalışabilmesi için absorpsiyonlu soğutma makinası Jeneratörünün ihtiyacı olan minimum
1S1 miktarının karşılanması gerekmektedir. Gerekli olan bu 1S1 ihtiyacının karşılanması için kollektör yüzey alanının belirlenmesi gerekmektedir. Takip eden bu bölümde absorpsiyonlu soğutma sistemi kollektör yüzey 
alanın belirlenmesi için gerekli olan eşitlikler verilmiştir. Kollektör yüzey alanı aşağıdaki şekilde hesaplanabilir.

$$
A_{c}=\frac{Q_{J}}{\eta I_{E}}
$$

burada $Q_{J} \quad$ absorpsiyonlu soğutma makinası jeneratörünün ihtiyacı olan minimum 1sı miktarı, $\eta$ kollektör sisteminin toplam verimidir. $I_{E}$ ise eğik düzleme gelen güneş 1şınım miktarını gösterir ve aşağıdaki formülle hesaplanır.

$$
I_{E}=I R
$$

burada $R$ dönüşüm faktörüdür ve Tablo 5 'te verilmiştir [10]. I ise yatay düzleme gelen günlük toplam güneş ışınım miktarıdır ve aşağıdaki eşitlikle bulunur [11].

$$
I=I_{1}+\left.\left(I_{0}-I_{1}\right)\left|\operatorname{Sin}\left[\frac{\pi}{365}(n+5)\right]\right|\right|^{1.5}
$$

Burada 7 yıllık ölçülen değerlerden tespit edilen $I_{0}$ ve $I_{1}$ fonksiyon parametreleri Kahramanmaraş kenti için sirasiyla 25,36 ve 4,5 değerleridir. Burada $n$ terimi günü göstermektedir.

Tablo 5. Enleme, mevsime ve kollektör eğim açısına göre $R$ faktörleri [10].

\begin{tabular}{ccccc}
\hline Enlem & \multicolumn{4}{c}{ Kollektör eğim açısına göre R faktörleri } \\
& $\mathbf{1 5}^{\circ}$ & $\mathbf{3 0}^{\circ}$ & $\mathbf{4 5}^{\circ}$ & $\mathbf{6 0}^{\circ}$ \\
\hline $36^{\circ}$ & 1,154 & 1,229 & 1,221 & 1,129 \\
$38^{\circ}$ & 1,168 & 1,257 & 1,260 & 1,177 \\
$40^{\circ}$ & 1,183 & 1,286 & 1,301 & 1,227 \\
$42^{\circ}$ & 1,199 & 1,316 & 1,344 & 1,280 \\
\hline
\end{tabular}

\section{BULGULAR VE TARTISSMA}

$\mathrm{Bu}$ çalışmada bir apartman dairesinin soğutma sistemi; güneş enerjisi destekli Su-Lityum Bromür $\left(\mathrm{H}_{2} \mathrm{O}\right.$ $\mathrm{LiBr}$ ) karışımı kullanan tek etkili absorpsiyonlu soğutma makinası, güneş kollektörleri ve dairenin ana bileşenleri göz önüne alınarak incelenmiştir. Dairenin soğutma sisteminin hesaplamaları, odaların ortam sıcaklığını istenilen sıcaklıkta sabit tutabilmek için EES ve MATLAB programları kullanılarak yazılan kod ile yapılmıştır. Hesaplamalarda, Tablo 6'da dairenin soğutulduğu 5 aylık periyot için verilen, Kahramanmaraş kentinin ortalama dış hava sıcaklıkları göz önüne alınmıştır. Diğer aylar dairenin soğutma ihtiyacının olmadığı göz önüne alınmıştır.
Tablo 6. Kahramanmaraş kenti için aylık ortalama dış hava sicaklıkları.

\begin{tabular}{lc}
\hline Aylar & Ortalama dış hava sıcaklığı \\
\hline Mayıs & 20,80 \\
Haziran & 25,88 \\
Temmuz & 28,51 \\
Ağustos & 27,98 \\
Eylül & 24,43 \\
\hline
\end{tabular}

Hesaplamalar boyunca odaların ve koridorun ortam sıcaklığının sabit olduğu kabul edilmiştir. Odaların iç ortam sicaklığ $24{ }^{\circ} \mathrm{C}$ ve koridorun ortam sicaklığ $27^{\circ} \mathrm{C}$ alınmıştır. Hesaplamalar sonunda elde edilen dairenin toplam artırımsız 1sı kazancı $Q_{\text {Oda }}$ bileşenleri; iç ve diş duvarlardan, iç kapılardan ve pencerelerden kaynaklanan 1sı kazancı Şekil 4'te verilmiştir.

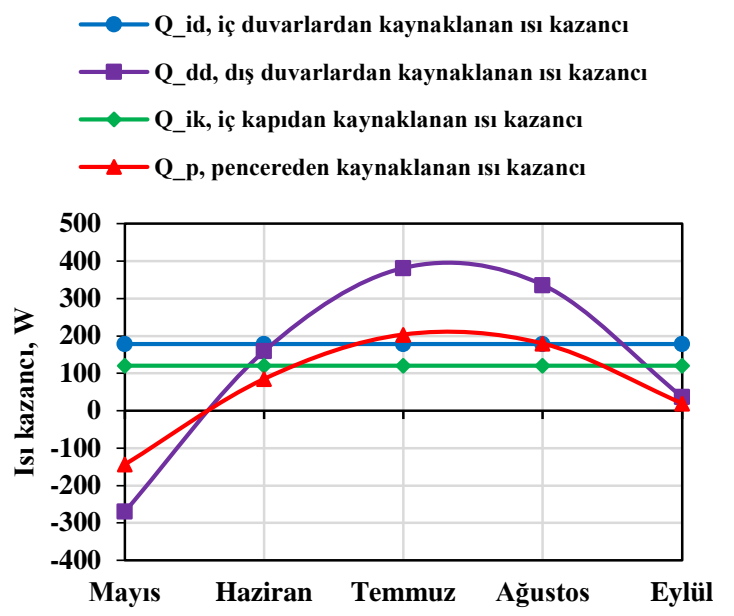

Şekil 4. Apartman dairesinin toplam artırımsız 1s1 kazancı bileşenleri değişimleri.

Şekil 4'te görüldüğü üzere iç duvarlardan ve iç kapılardan kaynaklanan isı kazancı sabit kalmıştır. Bununla birlikte diş duvarlardan ve pencerelerden kaynaklanan 1Sı kazancı hava sıcaklığına bağlı olarak değişim göstermiş ve en büyük değere Temmuz ayında ulaşmıştır. Ayrıca, Mayıs ayında dış duvarlardan ve pencereden kaynaklanan 1S1 kazanc1 yerine 1S1 kayb1 olduğu gözlemlenmiştir.

Birleştirilmiş artırım katsayısı $Z$ değeri güneye bakan daire için 1,2 bulunmuştur. Dairenin toplam artırımsız 1S1 kazancına artırım katsayısı uygulanmadığında ve uygulandığında elde edilen sonuçlar Şekil 5 'te verilmiştir. 


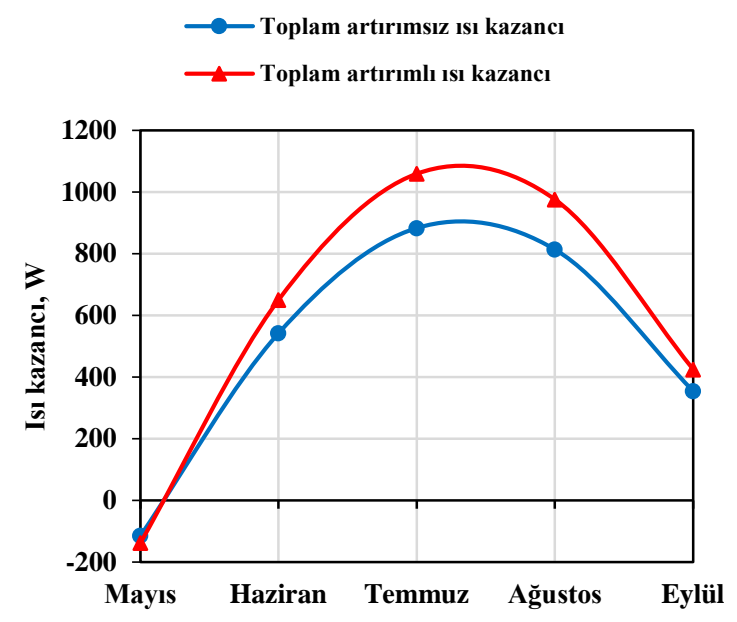

Şekil 5. Apartman dairesinin toplam artırımsız ve artırımlı 1sı kazancı değişimleri.

Şekil 5'te de görüldüğü gibi 1S1 kazancı miktarı arttıkça birleştirilmiş artırım katsayısının dairenin toplam 1sı kazancı miktarına etkisi artmıştır. Bu yüzden en büyük artım en fazla 1sı kazancının olduğu Temmuz ayında görülmüştür.

Şekil 6'da dairenin toplam artırımlı $Q_{\text {Oda }} \times Z$, hava sızıntısı $Q_{S}$, insanlardan olan $Q_{\text {insan }}$ ve cihazlardan olan $Q_{\text {Cihaz }}$ 1sı kazancı verilmiştir.

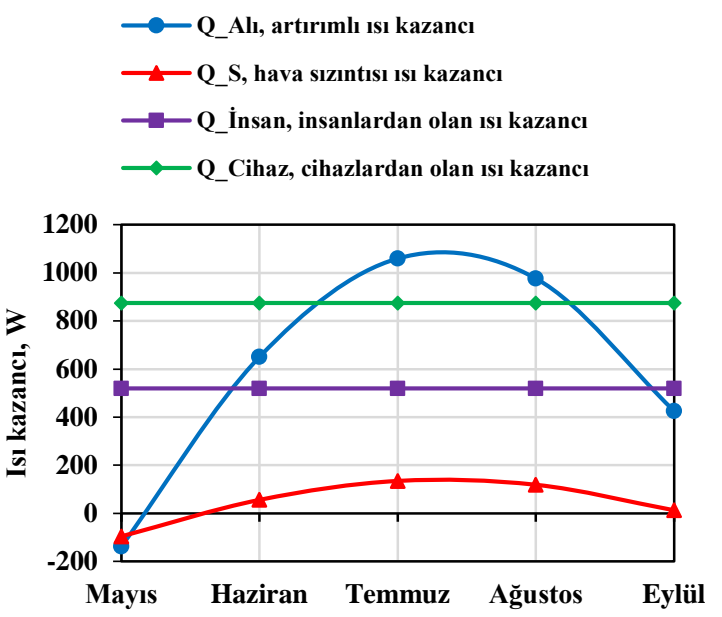

Şekil 6. Apartman dairesinin toplam artırıml, hava sızıntısı, insanlardan ve cihazlardan olan 1sı kazancı değişimleri.

Şekil 6'da görüldüğü üzere insanlardan ve cihazlardan kaynaklanan ısı kazancı sabit kalmıştır. Hava Sızıntıs1 1S1 kazancinın dairenin toplam artırımlı 1S1 kazancına göre daha küçük değerlerde olduğu görülmüştür. Ayrıca, Mayıs ayında hava sızıntısından kaynaklanan 1s1 kazanc1 yerine 1s1 kayb1 olduğu gözlemlenmiştir.
Hesaplamalar sonunda elde edilen dairenin toplam soğutma 1sı yükü $Q_{\text {Daire }}$ Tablo 7'de verilmiş ve en fazla ısı kazancının Temmuz ayında olduğu bulunmuştur.

Tablo 7. Apartman dairesinin toplam soğutma 1sı yükü değerleri.

\begin{tabular}{lc}
\hline Aylar & $\begin{array}{c}\text { Apartman dairesinin toplam } \\
\text { soğutma isı yükü }(\mathbf{k W})\end{array}$ \\
\hline Mayıs & 1,1617 \\
Haziran & 2,1019 \\
Temmuz & 2,5894 \\
Ağustos & 2,4898 \\
Eylül & 1,8330 \\
\hline
\end{tabular}

$\mathrm{Bu}$ çalışmada bir dairenin soğutma 1s1 yükünü karşılamak için güneş enerjisi destekli Su-Lityum Bromür $\left(\mathrm{H}_{2} \mathrm{O}-\mathrm{LiBr}\right)$ karışımı kullanan tek etkili absorpsiyonlu soğutma makinası kullanılmıştır. Tablo 4'te verilen kütle ve enerji denge denklemleri kullanılarak absorpsiyonlu soğutma makinasının enerji analizi her bir sistem elemanı için yapılmıştır. Sistemdeki her nokta için sıcaklık, basınç, entalpi ve konsantrasyon özellikleri EES programıyla hesaplanmış ve Tablo 8'de verilmiştir.

Tablo 8. Absorpsiyonlu soğutma makinası sistemindeki her nokta için özellikler.

\begin{tabular}{cccccc}
\hline Nokta & Akışkan & $\begin{array}{c}\mathbf{T} \\
{\left[{ }^{\mathbf{0}} \mathbf{C}\right]}\end{array}$ & $\begin{array}{c}\mathbf{P} \\
{[\mathbf{k P a}]}\end{array}$ & $\begin{array}{c}\mathbf{h} \\
{[\mathbf{k j} / \mathbf{k g}]}\end{array}$ & $\begin{array}{c}\mathbf{x} \\
{[\mathbf{\%}]}\end{array}$ \\
\hline $\mathbf{0}$ & $\mathrm{H}_{2} \mathrm{O}$ & 5 & 101.3 & 21.12 & - \\
$\mathbf{1}$ & $\mathrm{H}_{2} \mathrm{O}-\mathrm{LiBr}$ & 40 & 1.403 & 90.82 & 0.541 \\
$\mathbf{2}$ & $\mathrm{H}_{2} \mathrm{O}-\mathrm{LiBr}$ & 46 & 7.381 & 103.4 & 0.541 \\
$\mathbf{3}$ & $\mathrm{H}_{2} \mathrm{O}-\mathrm{LiBr}$ & 70 & 7.381 & 153.6 & 0.541 \\
$\mathbf{4}$ & $\mathrm{H}_{2} \mathrm{O}-\mathrm{LiBr}$ & 80 & 7.381 & 185.8 & 0.581 \\
$\mathbf{5}$ & $\mathrm{H}_{2} \mathrm{O}-\mathrm{LiBr}$ & 55 & 7.381 & 136.3 & 0.581 \\
$\mathbf{6}$ & $\mathrm{H}_{2} \mathrm{O}-\mathrm{LiBr}$ & 55 & 1.403 & 136.3 & 0.581 \\
$\mathbf{7}$ & $\mathrm{H}_{2} \mathrm{O}$ & 80 & 7.381 & 2649 & - \\
$\mathbf{8}$ & $\mathrm{H}_{2} \mathrm{O}$ & 40 & 7.381 & 167.5 & - \\
$\mathbf{9}$ & $\mathrm{H}_{2} \mathrm{O}$ & 12 & 1.403 & 167.5 & - \\
$\mathbf{1 0}$ & $\mathrm{H}_{2} \mathrm{O}$ & 12 & 1.403 & 2523 & - \\
\hline
\end{tabular}

Tablo 8'de verilen değerlere sahip güneş enerjisi destekli Su-Lityum Bromür $\left(\mathrm{H}_{2} \mathrm{O}-\mathrm{LiBr}\right)$ karışımı kullanan tek etkili absorpsiyonlu soğutma makinasının COP değeri 0,8052 bulunmuştur. Daha sonra absorpsiyonlu soğutma makinası jeneratörünün ihtiyacı olan minimum 1sı miktarı $Q_{J}$ hesaplanmış ve Tablo 9'da verilmiştir. En yüksek $Q_{J}$ miktarı Temmuz ayında 3,216 $\mathrm{kW}$ olarak bulunmuştur.

Jeneratörün ihtiyacı olan minimum ısıyı karşılamak için verimi \%51.97 olan vakum tüplü kollektör ve verimi \%43.7 olan düz plakalı kollektör kullanılmıştır [8]. Minimum kollektör yüzey alanı her iki kollektör için hesaplanmış ve Tablo 10'da verilmiştir. 
Tablo 9. Absorpsiyonlu soğutma makinası jeneratörünün ihtiyacı olan minimum 1sı miktarı.

\begin{tabular}{lc}
\hline Aylar & $\begin{array}{c}\text { Jeneratörün ihtiyacı olan } \\
\text { minimum Isı miktarı (kW) }\end{array}$ \\
\hline Mayıs & 1,443 \\
Haziran & 2,610 \\
Temmuz & 3,216 \\
Ağustos & 3,092 \\
Eylül & 2,276 \\
\hline
\end{tabular}

Tablo 10. Jeneratörünün ihtiyacı olan minimum 1sıyı karşılamak için gerekli olan kollektör yüzey alanları.

\begin{tabular}{lcc}
\hline Aylar & $\begin{array}{c}\text { Vakum tüplü } \\
\text { kollektör } \\
\boldsymbol{\eta}=\mathbf{\% 5 1 . 9 7}\end{array}$ & $\begin{array}{c}\text { Düz plakalı } \\
\text { kollektör } \\
\boldsymbol{\eta}=\mathbf{\% 4 3 . 7 0}\end{array}$ \\
\hline Mayıs & 8,6225 & 10,2542 \\
Haziran & 14,4814 & 17,2219 \\
Temmuz & 18,0606 & 21,4784 \\
Ağustos & 19,2088 & 22,8440 \\
Eylül & 17,1892 & 20,4422 \\
\hline
\end{tabular}

Tablo 10'da da görüldüğü gibi kollektör yüzey alanı jeneratörün ihtiyacı olan minimum 1sı miktarına $\left(Q_{J}\right)$ ve $I_{E}$ eğik düzleme gelen güneş ışınım miktarına bağlı olarak en yüksek Ağustos ayında düz plakalı kollektör için 22,84 $\mathrm{m}^{2}$ ve vakum tüplü kollektör için $19,20 \mathrm{~m}^{2}$ bulunmuştur.

\section{SONUÇLAR}

$\mathrm{Bu}$ çalışmadan çıkarılan sonuçlar aşağıda sıralanmıştır.

1. Sistem tasarımında dairenin soğutma ihtiyacını karşılamak için minimum 19,20 $\mathrm{m}^{2}$ kollektör yüzey alanına sahip vakum tüplü kollektör kullanılması uygun olmaktadır.

2. Absorpsiyonlu soğutma makinası 1sı ihtiyacının tamamını kollektör kullanılarak karşılanamaması durumunda ise jeneratöre verilmesi gereken ısının kalanı elektrik veya doğal gaz ile çalışan boyler gibi diğer enerji kaynaklarından sağlanmalıdır.

\section{SEMBOLLER}

a Sizdırganlık katsayısı $\left[\mathrm{m}^{3} / \mathrm{mh}\right]$

d Uzunluk [m]

h Isı taşınım katsayısı $\left[\mathrm{W} / \mathrm{m}^{20} \mathrm{C}\right]$

$\mathrm{H}$ Bina durum katsayısı $\left[\mathrm{kJ} / \mathrm{m}^{30} \mathrm{C}\right]$

$\mathrm{k} \quad$ Isı iletim katsayıs $\left[\mathrm{W} / \mathrm{m}^{\circ} \mathrm{C}\right]$
I Güneş 1şınım miktarı $\left[\mathrm{W} / \mathrm{m}^{2}\right]\left[\mathrm{Mj} / \mathrm{m}^{2}\right.$. gün]

l Kapı ve pencerelerin açılan uzunlukları [m]

n Gün [birimsiz]

O Oda durum katsayısı [birimsiz]

R Dönüşüm Faktörü [birimsiz]

$\mathrm{U}$ Toplam $1 \mathrm{~s} 1$ transfer katsayıs $\left[\mathrm{W} / \mathrm{m}^{2}{ }^{\circ} \mathrm{C}\right]$

$\Delta \mathrm{T}$ Sicaklık Fark $\left[{ }^{\circ} \mathrm{C}\right]$

Z Birleştirilmiş artırım katsayısı [birimsiz]

Q Is1 [W]

\section{Yunan Sembolleri}

$\eta$ Kollektör sisteminin toplam verimi [\%]

\section{Alt indisler}

c Düzeltme Faktörü

d Duvar

dk Durum katsayısı

diş Diş

D Birleştirilmiş artırım

e Köşe açıklıkları etkisi

H Yön faktörü

iç İç

ik İç kapı

j Jeneratör

p Pencere

S Hava sizıntısı

S Siva

t Tuğla

E Eğim

W Kat yükseliği

\section{KAYNAKLAR}

[1] Dinçer İ., Erdallı Y., "Absorpsiyonlu soğutma sistemlerinin rolü ve etkinliği”, Termodinamik, 5, 31-37, 1993.

[2] Eskin N., Türkmen H. I., "Konut dışı binaların soğutma yüklerinin transfer fonksiyonu yöntemi ile hesaplanması", VI. Ulusal Tesisat Mühendisliği Kongresi Ve Sergisi,İzmir, 1-12, 2003. 
[3] Kent E.F., Kaptan İ.N., "İzmir ilindeki elli yatakli bir otel için güneş enerjisi destekli ısitma ve absorbsiyonlu soğutma sisteminin teorik incelenmesi” IX. Ulusal Tesisat Mühendisliği Kongresi, İzmir, 163-170, 06-09 Mayıs 2009.

[4] Kuyumcu M.E., Şahin H.E, Yumrutaş R., "Güneş enerjisi destekli absorpsiyonlu soğutma sistemi ile buz pistinin soğutulmasının teorik incelenmesi”, TTMD Isıtma, Soğutma, Havalandırma, Klima, Yangın ve Sıhhi Tesisat Dergisi, 96, 24-31, 2015.

[5] Onan C., Özkan D.B., Erdem S., "Exergy analysis of a solar assisted absorption cooling system on an hourly basis in villa applications”, Energy, 35, 5277-5285, 2010.

[6] Cimşit C., Öztürk İ.T., "Buhar sıkıştırmal1absorbsiyonlu çift kademeli soğutma çevrimi ve alternatif çevrimlerle karşılaştırılması", Isı Bilimi ve Tekniği Dergisi, 34(1), 19-26, 2014.

[7] Bozkaya B., Akdemir Ö., “Güneş enerjili NH3-H2O absorpsiyonlu soğutma sisteminin İzmir ili için incelenmesi”, X. Ulusal Tesisat Mühendisliği Kongresi, İzmir, 1405-1413, 13-16 Nisan 2011.

[8] Öz E.S., Özbaş E., Dündar R., "Vakum tüplü güneşli su 1sitma sistemi ile standart düz kollektörlü güneşli su 1sitma sistemlerinin performans ve verimlerinin deneysel olarak karşılaştırılması", VIII. Ulusal Tesisat Mühendisliği Kongresi, İzmir, 991-999, 25-28 Ekim 2007.

[9] Karakoç T. H., "Uygulamalı TS 825 ve Kalorifer tesisatı hesabı", IZOCAM, 1-36, 2001.

[10] Arınç Ü. D., "Güneşli su 1sıtıcılarının projelendirilmesi”, Elektrik Mühendisliği Dergisi, 344, 137-141, 1987.

[11] Bulut H., Büyükalaca O., "Simple model for the generation of daily global solar-radiation data in Turkey”, Applied Energy, 84, 477-491, 2007. 